\title{
PLANIFICACIÓN ESTRATÉGICA EN UN CONTEXTO COYUNTURAL DE CRISIS EN LA EMPRESA TURÍSTICA
}

\author{
Manuel Izaguirre Sotomayor
}

\section{RESUMEN}

A propósito de un caso, se pretende destacar la importancia de la planificación estratégica en un contexto coyuntural de crisis para convertirla en oportunidad.

Palabras clave: planificación estratégica, crisis, empresa turística.

\section{INTRODUCCIÓN}

El propósito del presente artículo es remarcar la importancia del pensamiento estratégico en la planificación empresarial turística; importancia que se ve incrementada en épocas de crisis o turbulencia interna o externa a la empresa, como sucedió con el ataque terrorista a las Torres Gemelas del 11 de septiembre del 2001.

Precisamente el papel que jugó la planificación estratégica en el futuro de la empresa Grantour Perú S. A., líder en el mercado receptivo japonés, es el ejemplo de su trascendencia.

Hasta el fatídico 9/11 Grantour Perú se dedicaba exclusivamente al mercado japonés. Al producirse el ataque terrorista a las Torres Gemelas, de la noche a la mañana se vio sin clientes, dado que le fueron canceladas todas las reservaciones realizadas.
Una de las razones por las que la empresa permanece en el mercado es que sus directivos reaccionaron rápidamente aplicando el plan de contingencia que elaboraron de inmediato.

Por lo tanto, considerando el accionar de Grantour Perú en el escenario del ataque terrorista a las Torres Gemelas, ilustrativo del adecuado desenvolvimiento de una empresa turística en el contexto de una crisis externa no controlable, lo presentamos como caso de estudio para el ámbito académico.

\section{CONCEPTUALIZACIÓN DEL DESARROLlO DE LA EMPRESA EN EL CONTEXTO DE LA GLOBALIZACIÓN}

Una de las fortalezas que tenía la empresa Grantour Perú al producirse el ataque terrorista fue haber planificado estratégicamente el desarrollo de su competitividad en el contexto de la globalización. Lo hizo porque sus ejecutivos estaban convencidos de que este fenómeno había creado interdependencia de los mercados, convirtiéndolos en un solo mercado mundial que obligaba por lo tanto a conocer al detalle su dinámica, pensar en forma integral y orientar las actividades de la empresa hacia actividades de alto valor agregado, lo que unido a la reducción de costos de los servicios, la harían globalmente competitiva. Operar solo en función del mercado nacional era estar fuera de la tendencia actual. 
La empresa había impuesto también el conocimiento -es decir, la tecnología- como la más importante variable dentro de la función de producción global, que afecta al capital, a la mano de obra o a ambos. Su comprensión requería romper con los viejos paradigmas de la gestión y conducción empresarial, priorizando el activo humano como único fundamento del adecuado uso del conocimiento y la tecnología de la información, haciendo posible la implementación de una persistente política en pro de la calidad en la empresa, comprometiéndola con la tecnología, la exportación y la redistribución del ingreso como únicas estrategias para forjar una realidad más justa y equitativa, al estar sintonizados con el nuevo paradigma de desarrollo económico al que ella obligaba. Vale decir, modernizarse para exportar y exportar para desarrollarse en un mundo globalizado que avanza inexorablemente hacia el arancel cero.

Sus directivos eran conscientes de que tanto la creciente competencia mundial como los trastornos económicos, políticos y sociales exigían un liderazgo completamente revolucionario, que ponía a prueba todos los viejos paradigmas, modos de pensar y de actuar. Por lo tanto, tenían la certeza de que toda empresa que deseara mantenerse en el mundo globalizado debía lograr niveles adecuados de tecnología, productividad, competitividad y capacidad exportadora. Para ello requería generar excedente de capital y mano de obra calificada para invertirla en la actividad más rentable y segura a largo plazo: aumentar la capacidad exportadora de los paquetes turísticos.

Sabían asimismo que la combinación adecuada de algunos elementos básicos (política macroeconómica que asegure baja inflación, bajo déficit fiscal, educación, infraestructura física, así como mercado financiero y accionario sólido) genera la posibilidad de producir eficientemente. Pero esto solo se logra incorporando tecnología aplicada a los procesos de producción como punto de partida, para asegurar un flujo constante de conocimiento, capacitación y maquinaria, y pasar así a una segunda fase en la que la eficiencia en la producción, más la reducción de costos, mejoras en la calidad, diseño de los circuitos turísticos, materiales, empaque, comercialización, gerencia, entre otros, harían más productiva a la empresa.
Solo si se combina mayor productividad y menores costos de producción se obtiene un nivel suficiente de competitividad. Todo esto para alcanzar el fin último de los procesos económicos de producción: la redistribución del ingreso para lograr el objetivo superior de elevar el nivel de vida de nuestros trabajadores. Objetivo que se consigue en el marco de la globalización a través de la exportación, con el esfuerzo del sector productivo de una nación mediante la fórmula: tecnología, productividad y competitividad.

\section{DESARROLLO ECONÓMICO DE LA EMPRESA TURÍSTICA EN EL CONTEXTO DE LA GLOBALIZACIÓN}

El desarrollo competitivo de una empresa turística demanda la existencia de requisitos básicos indispensables como:

1. Una política macroeconómica que garantice baja inflación, alta inversión, bajo endeudamiento y presupuesto equilibrado.

2. Una acción estatal que asegure un liderazgo con visión de futuro, un plan integral de desarrollo turístico nacional, una política de desarrollo turístico incorporada como política de Estado, una capacidad gerencial en el ejercicio de su rol rector, una óptima infraestructura turística, personal calificado, adecuado ambiente de trabajo y financiamiento apropiado.

3. Una política nacional de desarrollo del turismo que propicie:

- Desarrollo equilibrado del mercado turístico, fomentando el accionar multisectorial y la protección técnica de los atractivos turísticos para garantizar su sostenibilidad a través del fortalecimiento de la imagen e identidad nacional.

- Construcción de la marca turística nacional y su adecuada gestión.

- Asignación presupuestal apropiada para poner en valor los recursos turísticos y satisfacer demandas del mercado priorizado.

- Formulación de la normatividad moderna, integral y coherente para el crecimiento sostenido del país en lo turístico, económico, social y político. 
- Promoción de la inversión privada para generar productos turísticos competitivos.

- Ejecución de un programa de concesiones y privatizaciones.

- Regulación adecuada del mercado turístico.

- Protección del patrimonio cultural y natural de la nación.

- Exoneración del IGV al paquete turístico integral.

- Educación de la población para que sus integrantes sean ellos mismos promotores del turismo.

- Búsqueda de concertación con todos los sectores públicos y privados que intervienen en el mercado turístico.

4. Una política de la calidad turística enfocada en los procesos centrados en la satisfacción del cliente interno y externo desde la primera vez, certificación institucional de la calidad turística, racionalización e informatización de todos los procesos con valor agregado, utilización de tecnología de punta en la automatización de los procesos, convirtiendo a la empresa en una agencia virtual para llegar a los navegantes informáticos.

5. Una política educativa enfocada en el aprendizaje más que en la enseñanza, que priorice la capacidad emprendedora en todos los niveles del sistema educativo nacional, así como la capacitación y entrenamiento del personal.

6. Una política de fortalecimiento de la infraestructura turística, para poner en valor los destinos turísticos priorizando el recurso turístico, la accesibilidad, la hotelería y la restauración.

7. Una política de fortalecimiento del mercado turístico y financiero para lograr su solidez.

\section{FASES DE DESARROLLO DE LA EMPRESA TURÍSTICA PARA LOGRAR LA COMPETITIVIDAD EN EL CONTEXTO DE LA GLOBALIZACIÓN}

\section{Fase inicial}

Al incorporar la tecnología aplicada a los procesos de producción, como punto de partida, Grantour
Perú se aseguró un flujo constante de conocimiento, capacitación, información y comunicación; se aseguró la financiación; se utilizaron los subsidios y se incentivó la investigación, desarrollo y transferencia tanto de la tecnología blanda (conocimiento) como de la tecnología dura (que tiene que ver con lo tangible o material).

\section{Fase intermedia}

Al cumplir con lo mencionado, la empresa pasó a la segunda fase de desarrollo en la que la eficiencia en la producción, más la reducción de costos en mano de obra y capital, junto a las mejoras en la calidad, diseño de los circuitos turísticos, materiales, empaque, comercialización y gerencia, entre otros, elevaron su productividad.

\section{Fase final}

Por otro lado, combinando el esfuerzo por aumentar la productividad y lograr menores costos de producción se obtuvo un nivel suficiente de competitividad. Asimismo, se implementaron estrategias claves de éxito como el enfoque en el turista, la innovación de servicios y la excelencia operativa. Todo esto para lograr la competitividad empresarial incrementando la comercialización de productos turísticos sobre la base de la calidad y la confiabilidad de los servicios, posicionando a Grantour Perú como operador turístico líder en el mercado emisor japonés.

Finalmente, la preocupación constante de sus ejecutivos fue alcanzar el fin último de los procesos económicos de producción: la redistribución del ingreso con el objetivo superior de elevar el nivel de vida de sus clientes, de sus accionistas, de sus familias, de las comunidades de los destinos turísticos que promociona, de sus trabajadores y de sus accionistas, contribuyendo así a la redistribución del ingreso nacional. Objetivo que se logra, en el marco de la globalización, a través de la exportación de productos turísticos de alta calidad y competitivos al más bajo precio posible en su nicho de mercado, haciendo posible el liderazgo del mercado masivo, receptivo, vacacional, por interés histórico o cultural, para japoneses de la tercera edad, encontrando el punto de equilibrio 
entre libre mercado y la protección del patrimonio cultural y natural.

Directivos y accionistas eran conscientes de que la creación de condiciones para la transferencia tecnológica, los esfuerzos para aumentar la productividad y los incrementos permanentes de competitividad sobre la base de una economía orientada a la exportación constituían la fórmula del éxito en el presente siglo. Además, compartían la idea de que los ejecutivos exitosos generan empresas exitosas, ofreciendo servicios de calidad, produciendo mayor satisfacción de necesidades, empleos e ingresos que, por un lado, generan ahorros e inversión y, por otro, incrementan el consumo de bienes y servicios que elevan la calidad de vida de la población.

\section{ENFOQUE ESTRATÉGICO}

El análisis estratégico del entorno interno y externo de la empresa, en el contexto del ataque terrorista a las Torres Gemelas, se focalizó en los aspectos político, económico, social, tecnológico, institucional y de mercado.

\subsection{Análisis externo}

\section{Fortalezas del Perú como destino turístico}

Considerado entre los cinco países con mayor megadiversidad del planeta, primero en diversidad de mariposas y orquídeas, segundo en diversidad de aves, mamíferos y peces, tercero más extenso del continente sudamericano, cuarto en bosques tropicales y anfibios, quinto en especies de flora y fauna, séptimo en reptiles, noveno en superficie forestal, poseedor de 25 mil especies de plantas (30\% endémicas), de los bosques tropicales con mayor diversidad de especies, de tres mil yacimientos arqueológicos -incluido Machu Picchu-, además de ser el centro mundial de endemismo y recursos genéticos.

Asimismo, tiene 84 microclimas de los 107 existentes, 28 tipos de clima de los 32 que hay en el mundo, una diversidad culinaria impresionante considerada entre las mejores 12 gastronomías del mundo, 42 grupos étnicos sobrevivientes, 12 familias lingüísticas, 45 lenguas vivas y diez patrimonios culturales de la humanidad (Complejo Arqueológico Chavín, Centro Histórico de Lima, ciudad del Cuzco, zona arqueológica de Chan Chan, Parque Nacional del río Abiseo, Santuario Histórico de Machu Picchu, Parque Nacional del Manu, Centro Histórico de Arequipa, Parque Nacional del Huascarán y Líneas de Nazca).

Construir las ventajas competitivas de un país depende más de la voluntad colectiva y no de los recursos físicos y naturales con que este cuenta. Es decir, en el caso del Perú, toda esta riqueza heredada había que convertirla en ventaja competitiva con el accionar de su gente y de su gobierno, contando con el poderoso aglutinante de una visión de futuro. No hacerlo le impediría ser un destino turístico líder no solo latinoamericano, sino mundial.

\section{Principales debilidades en la coyuntura analizada}

- Pérdida de liderazgo y autoridad del gobierno.

- En lo económico, el turismo generaba poca captación de divisas y, por lo tanto, casi nula redistribución interna de la riqueza y de generación de empleo.

- En lo social, ausencia de fortalecimiento de la identidad nacional, no integración de la sociedad peruana y carencia de adecuada vinculación con la comunidad internacional.

- En lo político, no existía complementariedad de los niveles nacional, regional y local, la institucionalidad no era sólida, no había valoración de lo local, y el Estado no asumía su rol rector en la difusión de la imagen del país. Esta situación generó marchas al Congreso y a Palacio de Gobierno, paros regionales, toma de aeropuertos, manejo inadecuado de la información por la prensa, asaltos, violaciones y asesinatos de turistas, rebrote del terrorismo y severa crisis recesiva, lo que configuraba al Perú como un destino turístico inseguro.

\subsection{Análisis interno}

En el ámbito interno la crisis económica mundial derivó en consecuencias globales como la recesión 
mundial de la economía, la retracción del turismo y el impacto sobre precios por la baja demanda, toda vez que en épocas de crisis la gente no gasta en viajes. Los destinos turísticos sufrieron un reordenamiento a nivel mundial y se cancelaron o postergaron las reservas realizadas, por razones de desconfianza e inseguridad.

Las secuelas empresariales fueron el replanteamiento estratégico de las empresas turísticas, la necesidad de incrementar la creatividad de la empresa privada para encontrar nuevos canales de distribución y nuevas rutas a destinos turísticos, la creación de oportunidades para incrementar el flujo turístico al Perú, penetrando agresivamente en el mercado europeo y en el asiático.

Esta situación demandaba la necesidad de una acción proactiva por parte del Estado para la promoción y desarrollo del turismo nacional con visión de futuro y para incrementar el atractivo del Perú como destino turístico seguro, teniendo en cuenta la dependencia de los viajeros modernos de Internet y de la web 2.0.

\section{REFORMULACIÓN DE LA VISIÓN EMPRESARIAL}

Frente a esta nueva e inesperada realidad, producto de la acción terrorista contra las Torres Gemelas, el directorio de Grantour Perú decidió de inmediato reformular su visión, centrada en valores que daban sustento a su filosofía institucional, y que fuera capaz de despertar ilusiones y construir un nuevo paradigma de gestión empresarial en respuesta a la crisis que enfrentaban. Al mismo tiempo reformularon sus objetivos inmediatos, mediatos y de largo plazo, cuya cristalización se sustentaba en la decisión de realizar en la empresa un cambio estratégico de dirección y de gestión, un cambio organizacional para adecuar la empresa a las reformas realizadas y un cambio de la cultura organizacional, conscientes de su importancia para el logro la competitividad empresarial.

\section{NUEVAS TENDENCIAS DEL TURISMO MUNDIAL}

Otro paso importante que realizaron los ejecutivos fue el análisis detenido de las nuevas tendencias del turismo mundial, en su afán de encontrar nichos alternativos de mercado.

Fue así que determinaron que la tendencia de la actividad turística mundial se orientaba al decrecimiento de la demanda por productos estandarizados, al incremento de jóvenes viajeros (140 millones de llegadas por año), al aumento creciente de la población con algún impedimento físico -que representaba 61 millones de personas discapacitadas con posibilidades de viajar (Keroul) -, así como al aumento sostenido de personas mayores de 60 años que demandan turismo termal o "para ponerse en forma".

Detectaron asimismo la existencia de polarización entre los que buscan el confort y lujo versus los que buscan la aventura y destinos exóticos; el respeto a la integridad, protección y realce del encanto de los destinos turísticos; participación y beneficio de las comunidades; conservación de los recursos naturales y culturales; el crecimiento de la demanda de viajes "a la medida" y de productos "no estandarizados"; y el surgimiento de nuevos clientes gracias al incremento de aerolíneas de bajo costo.

Por otro lado, el crecimiento del turismo de aventura se daba a tasas altas (15-30\%), el mercado de viajes de larga travesía para el 2020 sería de $24 \%$ del mercado total, se incrementaba la afición por los deportes náuticos y los safaris fotográficos $(7 \%)$, así como el gusto por la observación de la fauna (9\%).

Los ejecutivos de Grantour Perú también precisaron cuáles eran los tipos de actividad turística demandados por el mercado internacional y los nuevos requerimientos de ese mercado. En este sentido se comprobó que a los turistas les gustaba visitar parques nacionales y espacios protegidos (11\%), participar en fiestas populares $(12 \%)$ y practicar senderismo, trekking a pie o a caballo (19\%); así como el incremento de la demanda por destinos que permiten el contacto con el medio ambiente para visitar lugares culturales $(20 \%)$, por ecoturismo (Nature-Based) que crece a un ritmo anual de entre 25 y $30 \%$ (OMT), por turismo de aventura que creció $12 \%$ anual en los últimos cinco años (Adventure Travel Society), por turismo cultural que crecía entre 10 y $15 \%$ anual (OMT), por la búsqueda de rutas poco conocidas y por un mayor contacto con la población local. 
En ese contexto, Lima fue declarada Capital Gastronómica de América, representativa de un país de extraordinaria riqueza culinaria, producto de un mestizaje facilitado por la generosidad y creatividad de su gente, a partir de la confluencia de culturas diversas que han configurado su marca e influido en su proceso identitario. Los alimentos encontrados por los españoles ya incorporaban la información social de los pueblos preincas e incas, así como la comida de los conquistadores abarcaba expresiones de la cultura fenicia, romana, griega, cartaginesa, bárbara, musulmana (moros) y de los aborígenes de la península ibérica. Al ser la comida criolla "reflejo de un reflejo", un impulso cultural característico, expresa indudablemente un sentido de totalidad y de comunión entre el hombre y la naturaleza.

Los directivos de Grantour Perú, conscientes de que "si la velocidad de cambio en el sector empresarial turístico era menor que la velocidad de cambio del entorno" la empresa turística que conducían corría el riesgo de desaparecer del mercado, se dieron cuenta de que cambiar las cosas estaba en ellos mismos, lo fundamental era decidirse a hacerlo... ¡ahora! Y lo hicieron. Toda vez que si no se hace algo... nada cambiará, y lo que contribuyó al éxito en el pasado no garantiza el éxito en el futuro. Por consiguiente comprendieron que no debían sacrificar el mañana en el altar del ayer.

\section{DECISIÓN ESTRATÉGICA CLAVE}

Después del análisis sistemático y detallado de la actividad turística en el contexto de la coyuntura de crisis vivida, reconociendo y valorando su experticia de años en el turismo cultural para el mercado japonés, sobre todo en el nicho de mercado de la tercera edad, Grantour Perú decidió continuar en dicho nicho de mercado, ampliándolo para el mercado europeo. Decisión que se sintetizó en ocho metas por cumplirse en el siguiente lustro:

- Incrementar el turismo interno y egresivo.

- Terciarizar el transporte.

- Informatizar integralmente los procesos.

- Construir un banco deguías japoneses capacitados.

- Certificar en ISO-9002.

- Lograr una experiencia placentera de viaje (servicio diferenciado).

- Ingresar al mercado de la Unión Europea.
- Continuar siendo la empresa líder en turismo receptivo japonés.

En base a estos ocho objetivos, construyeron la escala estratégica para los siguientes cinco años.

Los objetivos para el año 2001 fueron los cuatro primeros: incrementar el turismo interno y egresivo, terciarizar el transporte, informatizar integralmente los procesos y construir un banco de datos de guías japoneses capacitados. Alcanzar estas metas demandaba contar con capacidades necesarias mínimas como: experiencia en negociación avanzada, realización del análisis del contexto interno y externo en procesos de reinvención, e identificación de actividades susceptibles de terciarización. Por lo tanto decidieron celebrar convenios y alianzas estratégicas, identificar los lugares donde capacitar a los guías japoneses en historia del Perú, diseñar e implementar software y hardware, y crear una nueva empresa de transporte o contratar de una existente.

Para el año 2002 se programó obtener la certificación en ISO-9002. Con tal propósito era necesario capacitar auditores internos y certificar solo procesos con valor agregado. Las medidas que tomaron fueron contratar a una empresa consultora especializada y a una empresa certificadora.

En el año 2003 se lograría una experiencia placentera integral de viaje a través del servicio diferenciado, para lo cual se requería realizar la evaluación del $100 \%$ de proveedores, así como valorar las alianzas estratégicas establecidas. Se implementaron city tours dentro y fuera del paquete turístico, y se instauraron alianzas estratégicas con hoteles, museos y líneas aéreas.

La meta del 2004 fue el ingreso al mercado de la Unión Europea, para lo cual identificaron que era indispensable contar con la capacidad de alcanzar el desarrollo institucional competitivo en el mercado turístico internacional. Establecieron el recojo de información del mercado turístico en el que se pretendía incursionar y confeccionaron un banco de datos con guías que dominaran el idioma francés.

Finalmente, en el año 2005 se propusieron continuar siendo la empresa líder en turismo receptivo japonés. 


\section{PROPOSICIÓN DE VALOR}

Con las decisiones estratégicas tomadas por el directorio, la gerencia general elaboróla proposición de valor de la empresa, que quedó sintetizada en el lema: "Nos dedicamos exclusivamente a

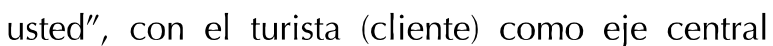
alrededor del cual se desenvolvería la empresa. La satisfacción de sus necesidades y hacer de su viaje una experiencia placentera podía lograrse solo con la implementación de tres estrategias claves: innovación de servicios, enfoque en el cliente y excelencia operativa.

El desempeño empresarial competitivo lo alcanzarían proponiéndose metas grandes, audaces y difíciles, construyendo marcadores de desempeño que facilitaran su monitoreo y evaluación, y consiguiendo el posicionamiento adecuado en el mercado turístico japonés, europeo y nacional.

Hacer realidad todo lo planificado imponía contar con el capital cognitivo adecuado; es decir, con el capital humano capacitado para lograrlo, concentrando el esfuerzo de la empresa en el adiestramiento de sus empleados. Se preocuparon por construir una nueva cultura organizacional centrada en valores, que fuera motivadora e incentivadora de la innovación. Por último, decidieron invertir en procurar un proceso correcto degestión y dirección, contextualizado en un cambio de la cultura y del enfoque organizacionales, basado en la planificación estratégica y toma de decisiones, considerando siempre su entorno competitivo, producto de la evaluación permanente del entorno interno y externo que la empresa realizaría.

Una vez formulada su proposición de valor, desarrollaron el modelo que les permitiría alcanzar los objetivos estratégicos de la empresa, cuyo eje central era la dedicación exclusiva al turista, articulando alrededor de ella sus cuatro estrategias claves: atención personalizada a sus clientes (turistas), alto rendimiento, servicio de apoyo al turista y priorización del turismo receptivo para Japón.

\section{INTERRELACIÓN DE LOS OBJETIVOS ESTRATÉGICOS}

Para lograr la atención personalizada a sus clientes priorizaron:
- Capacitación de guías japoneses en historia del Perú.

- Construcción de un sistema óptimo de información para la toma de decisiones. En este sentido se buscaría la alianza con las instituciones dedicadas al turismo, la actualización permanente del sitio web de la empresa y la elaboración de indicadores básicos de gestión.

- Conocimiento de las necesidades de los clientes (turistas) y ejecución solo de procesos que satisficieran esas necesidades.

- Establecimiento de alianzas con universidades e institutos de turismo.

- Innovación permanente de los servicios para nichos no explotados, resultado de la segmentación del mercado utilizando variables innovadoras o no usuales.

Para alcanzar un alto rendimiento en la empresa apostaron por:

- La automatización de los procesos con tecnología de punta para la virtualización de la empresa (Grantour virtual).

- El uso de herramientas modernas de gestión.

- El logro de la certificación ISO-9000.

- La celebración de alianzas estratégicas con los proveedores.

- El monitoreo de la salud financiera y estratégica de la empresa.

- La construcción de un sistema de información gerencial.

- La realización del estudio, elaboración y promoción de nuevos paquetes turísticos.

- La confección del plan operativo y del presupuesto anual.

- La construcción de un sistema de información para el turista.

- La elaboración de una base de datos de todos los proveedores.

Para establecer un servicio de apoyo al turista decidieron:

- Implementar city tours para diversión y compras fuera del paquete.

- Promover nuevos paquetes turísticos.

- Incrementar la información de apoyo al turista.

- Diferenciar todos sus servicios a través de la atención médica, servicio de compañía, entre otros. 
Para la priorización del turismo receptivo para Japón se tomaron las siguientes medidas:

- Elaboración de la base de datos de clientes actuales y potenciales.

- Monitoreo de la satisfacción del cliente.

- Fortalecimiento de la alianza estratégica con Grantour Japón y otros.

- Posicionamiento en el mercado de su ventaja competitiva de satisfacer al turista japonés.

- Información del flujo turístico de Japón al Perú.

\section{ESTRATEGIAS IMPLEMENTADAS}

En el entorno de las estrategias genéricas de desarrollo de Porter, los ejecutivos de Grantour Perú seleccionaron la diferenciación del servicio comoárea de acción, y la exclusividad como estrategia básica de diferenciación. Como estrategias de crecimiento de sus productos turísticos y de sus nichos de mercado, optaron por el crecimiento intensivo a través de la penetración del mercado conocido japonés, y para el mercado nuevo europeo se inclinaron por el crecimiento a través de la diversificación.
Finalmente, la estrategia de desarrollo competitivo que decidieron utilizar fue la del liderazgo, dada su posición en el mercado japonés; el principio de guerra mercadotécnica utilizado fue, justamente, dicha posición y la estrategia de guerra empleada fue la defensa.

Para el mercado europeo, la estrategia de desarrollo competitivo que eligieron fue la de especialistas, por ser un nicho de mercado nuevo; el principio de guerra mercadotécnica fue el de pequeña empresa, sin liderazgo en el mercado europeo; y la estrategia de guerra fue la guerrilla al inicio y el flanqueo por distribución después. El desenlace final de todo el esfuerzo realizado fue que no se perdió el liderazgo en el mercado japonés, sino por el contrario fortaleció la posición que tenía y logró penetrar exitosamente en el mercado europeo.

Estos son algunos reconocimientos a la empresa por los logros alcanzados, gracias a que sus ejecutivos supieron planificar y tomar decisiones estratégicas en el momento oportuno; y, lo más importante, las implementaron exitosamente porque recibieron el presupuesto para su ejecución.
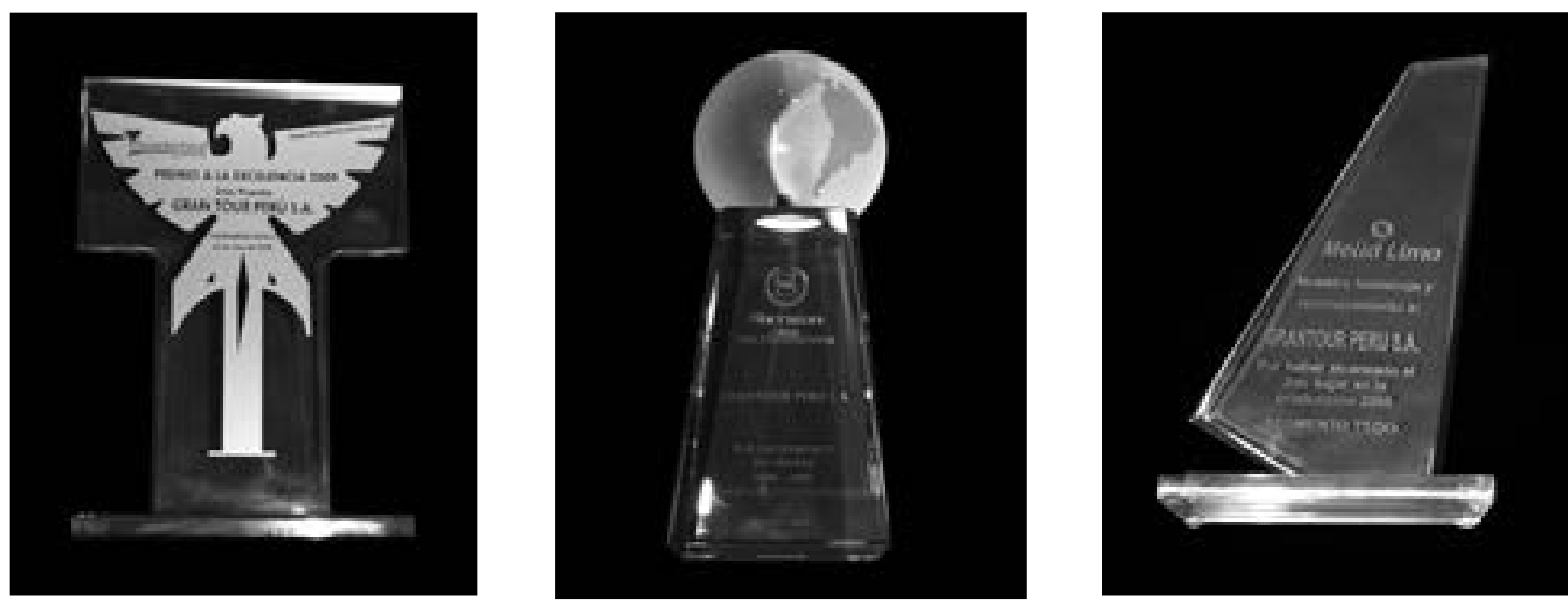

Evidentemente, el resultado obtenido fue el fruto de la planificación estratégica realizada y, sobre todo, de la implementación y evaluación rigurosa de todo lo planificado. 


\section{Bibliografía}

Braidot, N. (20). Neuromarketing.

Braidot, N. (2006). Venta inteligente. El Método de venta neurorelacional. Editorial puerto Norte Sur. Madrid. España.

Philip Kotler. (1998). Fundamentos de Mercadotecnia. Editorial Prentice Hall. Cuarta Edición.

Jean-Jacqes Lambin. (1995). Marketing Estratégico. Editorial Mc Graw Hill. Tercera Edición. Madrid.

Michael Solomón y Elnora Stuart. (s/f). Marketing: Personas Reales, Decisiones Reales. Editorial Prentice Hall.

Al Ries y Jack Trout. (2005). La guerra de la mercadotecnia. Editorial Mc Graw Hill.

Al Ries y Jack Trout. (1994). Las 22 Leyes Inmutables del Marketing. Editorial Mc Graw Hill.

Al Ries y Jack Trout. (2000). Posicionamiento. Editorial Mc Graw Hill. 2da Edición. 1992.

Simón Majaro. (1998). La Esencia de la Mercadotecnia. Editorial Prentice Hall.

William Stanton. (1997). Fundamentos de Marketing. Editorial Mc Graw Hill. Décima Edición. William Pride. (1997). Marketing: Conceptos y Estrategias. Editorial Mc Graw Hill.
Jacques Lambin, Jean. (1997). Marketing Estratégico. Edición Ediscience Internacional, Paris.

Ferrell, O, Harteline, M. \& Lucas, G. (2002). Estrategia de Marketing. Edición Internacional Thomson, México.

Mayorga David, Araujo Patricia. (2002). Marketing Estratégico en la empresa Peruana. Edición Universidad del Pacifico. Centro de investigación, Perú.

\section{Fuentes Cibernéticas}

El capital humano como estrategia competitiva en el sector turístico español. Recuperado de http:// www.uib.es/servei/sri/pdf/0607/07/IVPremi_ resumenAida.pdf

Estrategia competitiva. Recuperado de http:// www.joseacontreras.net/econom/Economia/ Megatendencias/page 3.htm

Concepto de marketing estratégico. Recuperado de http://www.marketing-xxi.com/concepto-demarketing-estrategico-15.htm

Plan estratégico de marketing. Recuperado de www. emagister.com/master/plan-estrategico-marketingts.htm. 